\title{
Choosing wisely: protocols, priorities and a postcard
}

\author{
REENA GEORGE
}

\begin{abstract}
Can a young doctor without training in communication skills use empathy as a compass for making ethical decisions? This narrative reflects on a young boy left alone with a paralysed dying father after six months of 'free' but futile treatment. Protocols should be weighed against prognosis and priorities when the disease is incurable.
\end{abstract}

Keywords: Communication skills, medical ethics, cancer treatment, empathy, palliative

"We will need an adult relative to stay with you in the hospital,"I told Sushil [name changed].

And then I learnt that there was no adult relative around Sushil and his little boy had sustained themselves through months of palliative chemotherapy by begging on the streets of the city.

\section{Protocols}

It was nearly thirty years ago. Sushil was in his early thirties, sent to us after palliative surgery for an advanced osteosarcoma of the femur. I was in my early twenties, starting radiation oncology training in a large metropolis. We were a small department in a large government hospital, with two telecobalt machines and a small selection of drugs for outpatient chemotherapy. Sushil came for several months for his weekly injections and blood tests. His sole companion on those frequent visits was his son, a boy of about ten.

One evening, Sushil limped into the outpatient radiotherapy clinic complaining of severe back pain. He skidded, fell down, and could not get up again - a sudden paralysis caused by metastatic spinal cord compression.

Authors: Reena George (reena.vellore@gmail.com), Department of Continuing Medical Education, Christian Medical College, Vellore, Tamil Nadu 632002 INDIA

To cite: George R. Choosing wisely: protocols, priorities and a postcard. Indian J Med Ethics. Published online first on November 9, 2021. DOI: 10.20529/IJME.2021.086.

Manuscript Editor:Vijayaprasad Gopichandran

(c) Indian Journal of Medical Ethics 2021
The department was locking up for the day and most colleagues had already left. Since we did not have a ward, we pleaded with the on-call orthopaedic registrar to admit the patient under their department. After some hesitation, the orthopaedic surgeon agreed.

\section{Postcards}

Sushil had no one he could contact immediately. His family lived hundreds of miles away, and the mobile phones that would one day reach the remotest hamlets in India had not yet entered our imaginations. I turned to the plain sturdy postcard - the most widely used means of communication, even by the illiterate.

Sushil knew his postal address, and I began to write a postcard every day. The pumpkin-yellow postcard, bare except for the imprinted brown stamp and address lines, could fit only a few sentences in legible Hindi. The message was always the same: "Sushil cannot walk and is seriously ill. He is admitted in

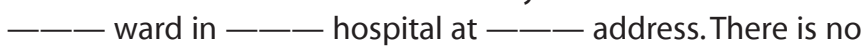
one else with his son. Please come soon."

For over two weeks, Sushil lay in a no-man's land between two departments. The orthopaedic surgeons had fractures to fix and patients to ambulate. Paralysed by spine secondaries, Sushil was "Nil orthopaedic". New to the hospital and to the city, afraid that the patient might lose his precious hospital bed, I dared not ask for more.

Anti-cancer treatment continued as per protocol. Sushil got ten fractions of palliative radiotherapy but the painless paralysed limbs did not improve. Each morning before reporting to work, I would visit the orthopaedic ward. Each day, I would ask if an adult relative had come. The answer was always in the negative. Father and son spoke very little, and I did not know what to say.

One morning, the boy stood beside an empty bed, the bare metal shining in the bright Indian sunlight.

"Pitaaji kahaan hain?" [Where is your father?], I asked, trying not to sound desperate. "Murr gaya." [He died].

Just two words. Quiet, fatalistic, unforgettable.

The silence ended when a bearded elderly man came down the ward, put a hand on the child's shoulder and said, "I left my village the day I received your postcard. My son died a few 
hours after I arrived. I will take my grandson back home today."

I never saw them again.

\section{Priorities}

Some decades later, after working on a Cochrane systematic review on metastatic spinal cord compression, I understood that Sushil had too many negative prognostic factors to have benefited from radiotherapy - he had a relatively radioresistant cancer with an acute and complete paraplegia (1).

Our knee-jerk adherence to protocol, like the exaggerated knee-jerks of a high spinal cord compression, had not helped Sushil make meaningful progress. The months of free palliative chemotherapy had been futile too. The suboptimal drugs and doses caused little physical toxicity, but the cumulative toxicities of time and money had done irreversible damage to someone who had precious little of both.

If I had known better then, I could have helped Sushil look beyond protocols to priorities. He might have returned home instead of begging on the streets, leaving a bereaved son with memories of those last desperate months. His wife could have spoken to her dying husband, instead of waiting for postcards written and read out by strangers.

But although I knew about better chemotherapy protocols that were available only in better-resourced countries, I did not know about the universal principles of benefits and burdens, autonomy and justice. Nor did I know how to explain that the disease was fatal.

Could I have done any better when I was young and unsupported?

Yes, if I had reconnected with what I had once known, but forgotten. If I had met Sushil before I studied medicine, I would have understood the gut-wrenching tragedy of a young father with an incurable cancer. And I would have soon found out that Sushil and his son were alone.

In becoming a doctor, I had lost part of the capacity to listen to his story. History- taking is the physician's finest tool, but I had used it only to check, "What does he have?" and "What should be done?" I had not plumbed, "Who is he? How is he managing? What does he hope for?"

That one question, more than anything else in my later years, has prompted me to offer offbeat options as one of several valid alternatives. And to offer those offbeat options sooner rather than later. Options such as an orphanage for the children of a dying mother; oral, rather than injectable systemic therapies; sometimes, heroic treatments in an attempt to prolong survival before an important milestone; or a milch cow to become the family's main source of income when the breadwinner is dying (2).

Across the world desperate families still leave-or losehomes and livelihoods seeking treatment for incurable disease. My medical history taking began to include

- "Where have you come from?"

- "What were you hoping for when you came this far?"

- "Who has come with you?"

- $\quad$ "How long will you be here?"

- "What is your profession?"

- "How are you raising money for this treatment?"

- "How old is your youngest child?"

Such questions frame the therapeutic chessboard, in the hope that the pieces will not fall off the table because of treatment recommendations.

Sushil on his crutches, had done all that he could to comply with the protocols on our therapeutic chessboard. I wish, at the beginning rather than at the end, I had discovered empathy enough to ask, "What would be important to me if I were in his shoes?"

Finally, when Sushil neither had shoes, nor the ability to use them, it was empathy that enabled us, amidst all that we did not know, to do what was needed-a dying father clung on to life until he could hand over his son; an old man journeyed far looking for his dying son; and a young doctor continued to write a postcard each day.

\section{Competing interests and funding: None declared.}

Acknowledgements: The author thanks Ms Shefali Mathew for her valuable comments on the first draft and for copyediting the manuscript.

\section{References}

1. George R, Jeba J, Ramkumar G, Chacko AG, Tharyan P. Interventions for the treatment of metastatic extradural spinal cord compression in adults. Cochrane Database Syst Rev 2015 Sep 4 [cited 2021 Nov 6]; 2015(9): CD006716. Available from: https://www.cochrane.org/ CD006716/SYMPT_interventions-treatment-spinal-cordcompression-due-spread-cancer

2. George R. Life's lessons lost...and learned. J Clin Oncol. 2010 Apr 1[cited 2021 Nov 6]; 28(10):1806-7. Available from: https:// ascopubs.org/doi/full/10.1200/JCO.2009.27.0413 